\title{
Electrical Conductivity Variation With Temperature of Irradiated Standard Malaysian Rubber(SMR)
}

\author{
Sanaa Mahmood Al-delaimy \\ Physics Department \\ Education college \\ University of Mosul, Mosul, Iraq
}

Received

Accepted

$13 / 4 / 2005$

$16 / 8 / 2005$

\begin{abstract}
الخلاصة

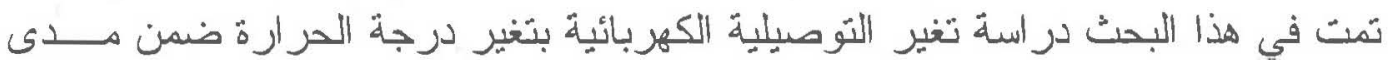

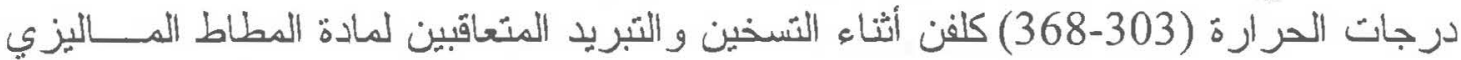

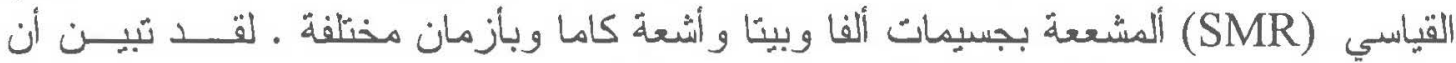

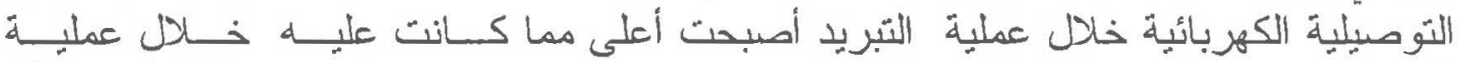

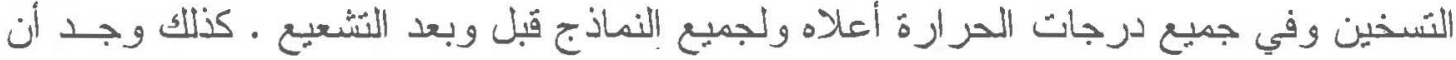

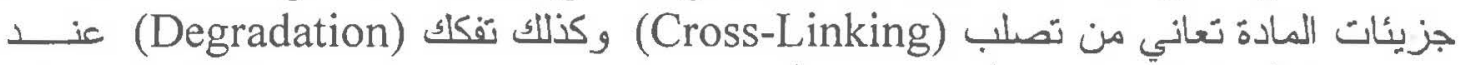

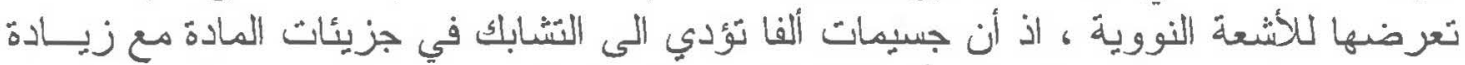

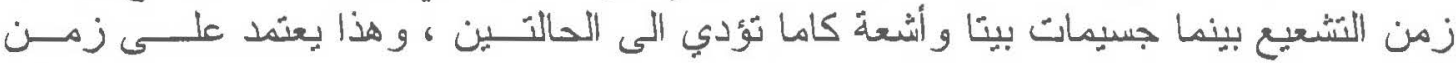
· التشعيع التعبع

\section{ABSTRACT}

Electrical conductivity variation with temperature in the range (303-368)K during heating and cooling has been studied for irradiated SMR material using Alpha and Beta - particles and Gammarays. It was found that the values of conductivity during cooling are higher than that during heating for all samples before and after irradiation. Also it appears that the molecules suffer from crosslinking during irradiation with Alpha-particles , while they suffer from degradation and cross-linking during irradiating with Beta-particles and Gamma-rays, depending on the irradiating time.

\section{INTRODUCTION}

Rubber is a natural substance characterized by elasticity ,water repetlence, and electrical resistance. It is one of the most versatile materials of construction being used throughout the world. A large number of products with specific physico-mechanical properties as well as the electrical properties can be made from rubber [1-3] .It is 
important to know the environmental effect on its characteristics and internal mechanisms involved in its operation. Many workers have studied the effect of heat, light, and nuclear radiation on the properties of rubber specially its thermal and electrical conductivity [3-7]. They have conclude that heat and radiation will change the properties of rubber by cross-linking reactions or by degradation process and this depends on the time of exposing to the effective agent or to the strength of the agent .

In this work the change in electrical conductivity by temperature change has been studied for SMR material irradiated by Alpha and Betaparticles and Gamma-rays with different periods of exposure .

\section{EXPERIMENTAL}

The SMR used in this work was locally produced material, and it was a sheet of $10 \times 10 \mathrm{~cm}^{2}$ area and $2 \mathrm{~mm}$ thickness which was cut to $1 \mathrm{~cm}^{2}$ area samples. The electrical conductivity was calculated by measuring the current flowing through the sample using ammeter type (Keithley), and the voltage , using voltmeter type (Data Precision 1351) and power supply type (L-H 52237 ). The sample was carried in a suitable unit. It was connected by an electrode directly on each side. The electrical circuit used is shown in figure (1).

For heating, a completely isolated oven was used with temperature regulator for controlling the samples temperature during the conductivity measurements which was carried out from 303 to $368 \mathrm{~K}$ under normal pressure. The change of electrical conductivity with temperature was investigated for samples without radiation and for samples irradiated by Alpha ,Beta-particles and Gamma-rays as follows in the table below:

\begin{tabular}{|c|l|l|l|l|}
\hline Source & Radiation & $\begin{array}{l}\text { Activity } \\
\text { (curie) }\end{array}$ & $\begin{array}{c}\text { Irradiation time } \\
\text { (days) }\end{array}$ & $\begin{array}{l}\text { Radiation energy } \\
\text { (Mev) }\end{array}$ \\
\hline${ }^{226} \mathrm{Ra}$ & $\alpha$ & 1 & 3,15 & $4.6,5.5,6.0,7.6$ \\
${ }^{90} \mathrm{Sr}$ & $\beta$ & 0.7 & 3,7 & 0.54 \\
${ }^{137} \mathrm{Cs}$ & $\gamma$ & 0.75 & 3,7 & 0.662 \\
\hline
\end{tabular}




\section{RESULTS AND DISCUSSION}

The equation used for calculating the electrical conductivity of SMR with and without irradiation through heating and cooling is :

$$
\sigma=\frac{\vartheta \times I}{A \times V}
$$

Where I is the current, $\vartheta$ is the average thickness, $\mathrm{A}$ is the cross section area , and $\mathrm{V}$ is the applied voltage. The results are shown in Figure (2) and it is clear that the conductivity increases with temperature increasing in heating curves .The cooling curve shows an irreversible behavior and the electrical conductivity in this curve is higher than that of heating curve at the same temperature. This is due to the elimination of some defects in the structure of the material [8]. Also it is clear that there is a linearity in the cooling curve up to $343 \mathrm{~K}$ but deviation from straight line is observed above this temperature. That is due to an effective decrease in the density of mobile ions within the sample [8] .

Figure (3) shows electrical conductivity variation with temperature of the SMR irradiated by Alpha-particles with different times . It is clear that the conductivity decreases with increasing the time of exposure. This is due to the reactions which had been taken place between the free radicals at the end of the chains of the rubber which is called cross-linking reactions .

Figure (4) shows the dependence of electrical conductivity on temperature of the SMR irradiated by $\beta$-particles. It can be seen that the electrical conductivity decreases when the samples irradiated for three days but when the irradiation time increased the conductivity starts to increase to reach that of non-radiated curve. This is the same behavior for samples irradiated by $\gamma$-rays that shown in Figure (5). This might be due to two steps :

First - The samples that have been irradiated for three days have the first stage of activation that will force the free radicals to react with each other and so a cross-linking reaction might be taken place .

Second - An increase in irradiation time will rupture the chemical bonds of the material [9] and that's called (Degradation), so there will be so many radicals produced and the material become more electrically conductive and began to lost its insolating properties .

We thing that more increasing in the irradiation time create unpaired electrons to which will refer the increase of electrical conductivity and so the total electrical conductivity will be due to electronic and ionic conduction, i.e :

$$
\sigma_{\mathrm{t}}=\sigma_{\mathrm{i}}+\sigma_{\mathrm{e}}
$$


Figure (6) illustrate the electrical conductivity variation with temperature of SMR irradiated by $\alpha, \beta$-particles and $\gamma$-rays under the same radiation time which is three days. It is clear that the (conductivity - temperature) relation for samples exposed to $\beta$-particles and $\gamma$-rays in temperature range $(303-368) \mathrm{K}$ are the same, that means they have the same effect on the conductivity of the samples. Also the figure shows that samples exposed to $\alpha$-particles have conductivity more than those exposed to $\beta$-particles and $\gamma$-rays and that is because of the effect of $\alpha$-particles which is less than $\beta$-particles and $\gamma$-rays with respect to the sample as a whole. And that is because of the penetration depth of $\alpha$-particles which is less than both, $\beta$-particles and $\gamma$-rays [10] .

The activation energy Ea. was calculated from the slopes of the fitted straight lines of the curves in figure (6) using the equation :

$$
\sigma=\sigma_{\circ} e^{-\mathrm{Ea} / \mathrm{KBT}}
$$

where $\sigma_{0}$ is a material constant, $\mathrm{K}_{\mathrm{B}}$ is boltzmann constant, and $\mathrm{T}$ is the absolute temperature .

The calculated $\mathrm{Ea}$ from the lower temperature curve part of figure(6) is about (0.2)eV (for $\beta$-particles and $\gamma$-rays) and (0.15) $\mathrm{eV}$ (for $\alpha$-particles). While the value of Ea calculated from the upper temperature curve part is about (0.6)eV (for $\beta$-particles and $\gamma$-rays) and about (0.58) $\mathrm{eV}$ (for $\alpha$-particles). This is also attributed to the effect of $\alpha$-particles which is applied only on the surface of the material compared with $\beta$-particles and $\gamma$-rays which penetrate deeper $[10,11]$.

\section{CONCLUSION}

1-SMR material undergoes cross-linking by the irradiation with $\alpha$ particles for the tested time .

2- The electrical conduction of SMR is temperature dependent and it is believed to be ionic .

3-SMR material irradiated by $\beta$-particles and $\gamma$-rays undergoes crosslinking and degradation depending on time of radiation .

4-Increasing the irradiation time by $\beta$-particles and $\gamma$-rays more than three days will increase the conductivity, and more exposed time probably initiate an electronic conduction beside the ionic .

\section{REFERENCES}

1-Seymour Z. Lewin, Microsoft Corporation, Encyclopedia 2002 (C) 1993-2001.

2-Abdel-Bary E.M., Fourth International Conference on Physics of Condensed Matter, April.18 ${ }^{\text {th }}-20$,University of Jordan,p.40-44 (2000) . 
3- Ismail M.N. , Nasr E.S., and Ghoneim A.M., Forth International Conference on physics of Condensed Matter,April. $18^{\text {th }}-20$, University of Jordan ,p.60-68 (2000).

4- Al-dabbag Z.B., Thesis , Science College ,Mosul Univ., Mosul ,Iraq (2001).

5- Abdul -Ameer K.F., Thesis, University of Baghdad ,Baghdad, Iraq. (1980), .

6- Sulayman N.B. , Al-gholami T.N. , J. Edu. Sci, Vol.12:103-117 (1991).

7-Al-Abbasi L.A., Thesis , University of Baghdad ,Baghdad , Iraq.(1997).

8- Ohan O.Z. , Manssur H.L. and Habobe N. F. , Al-Mustansiriyah J. of Sci, Vol. 4, No. 1(1991) .

9- Kapten H. Y., J. Appl. Poly. Sci. Vol. 64 , No. 7, p.(1291-1294) (1997) .

10- أنكا ، نزجمة عاصم عبد الكريم عزوز"مقدمة في الفيزياء النووية "،جامعة الموصـل،

11- Jonsher A. K. , Thin Solid Film, vol.1, p.213 (1971) .

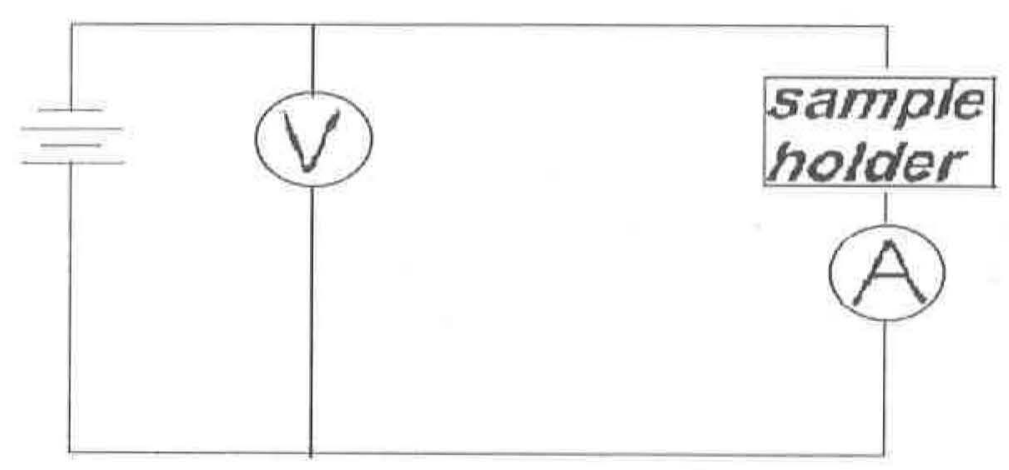

Fig.(1) The Electrical Circuit 


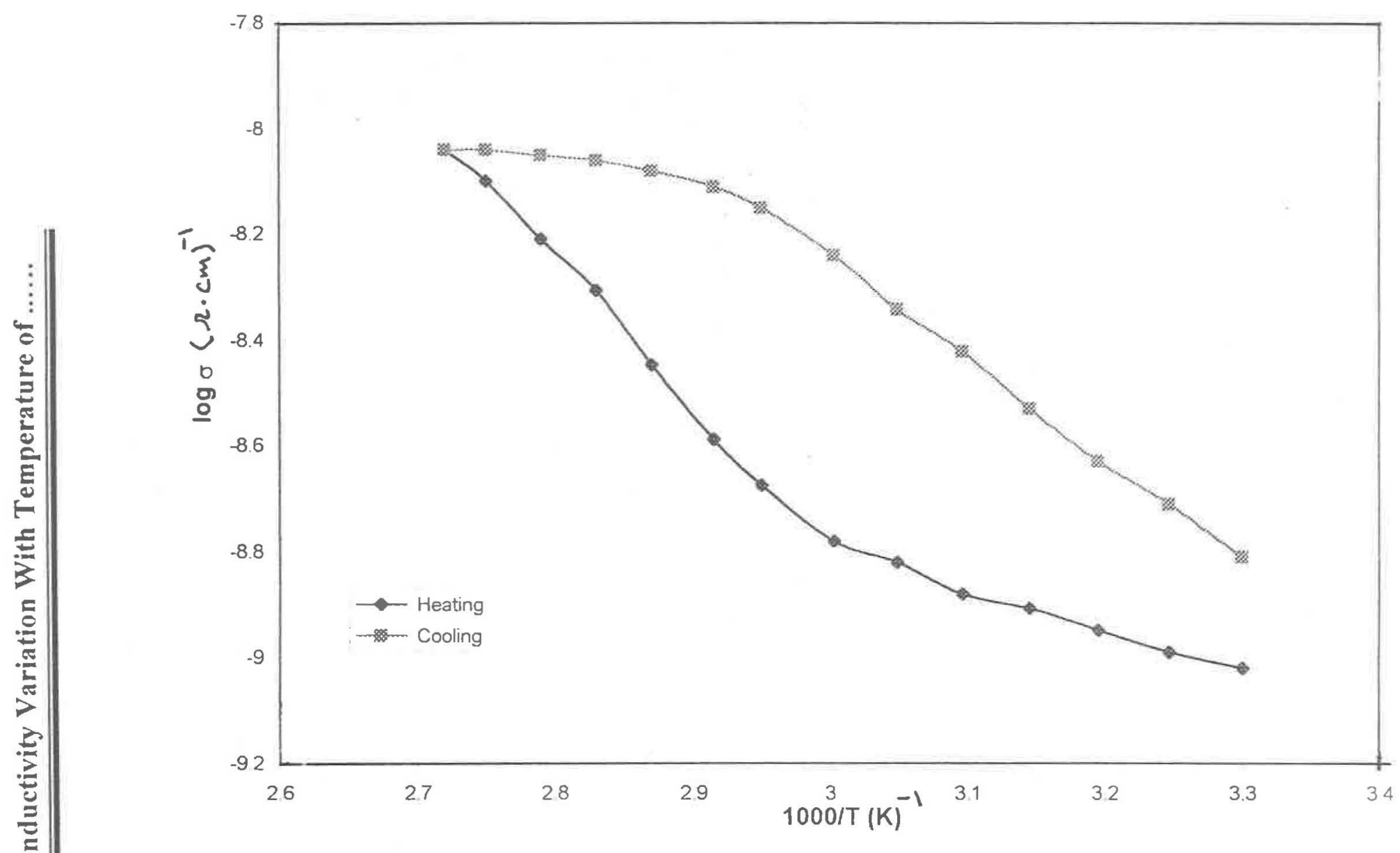

Fig.(2) electrical conductivity variation with temperature through heating \& cooling of SMR without irradiations 


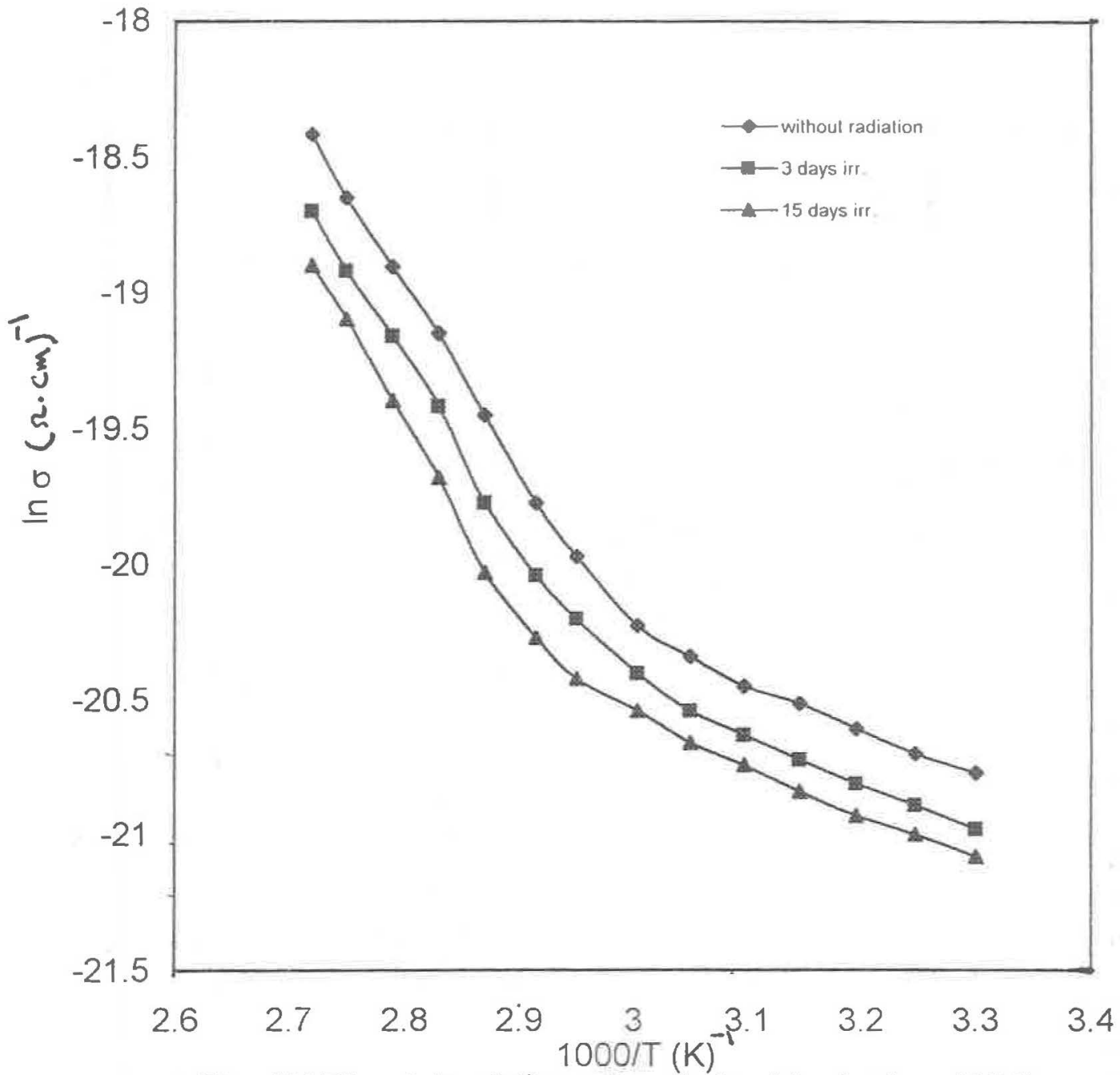

Fig (3)Electrical Conductivity Variation With Temperature of SMR Irradiated by Alpha-particles 


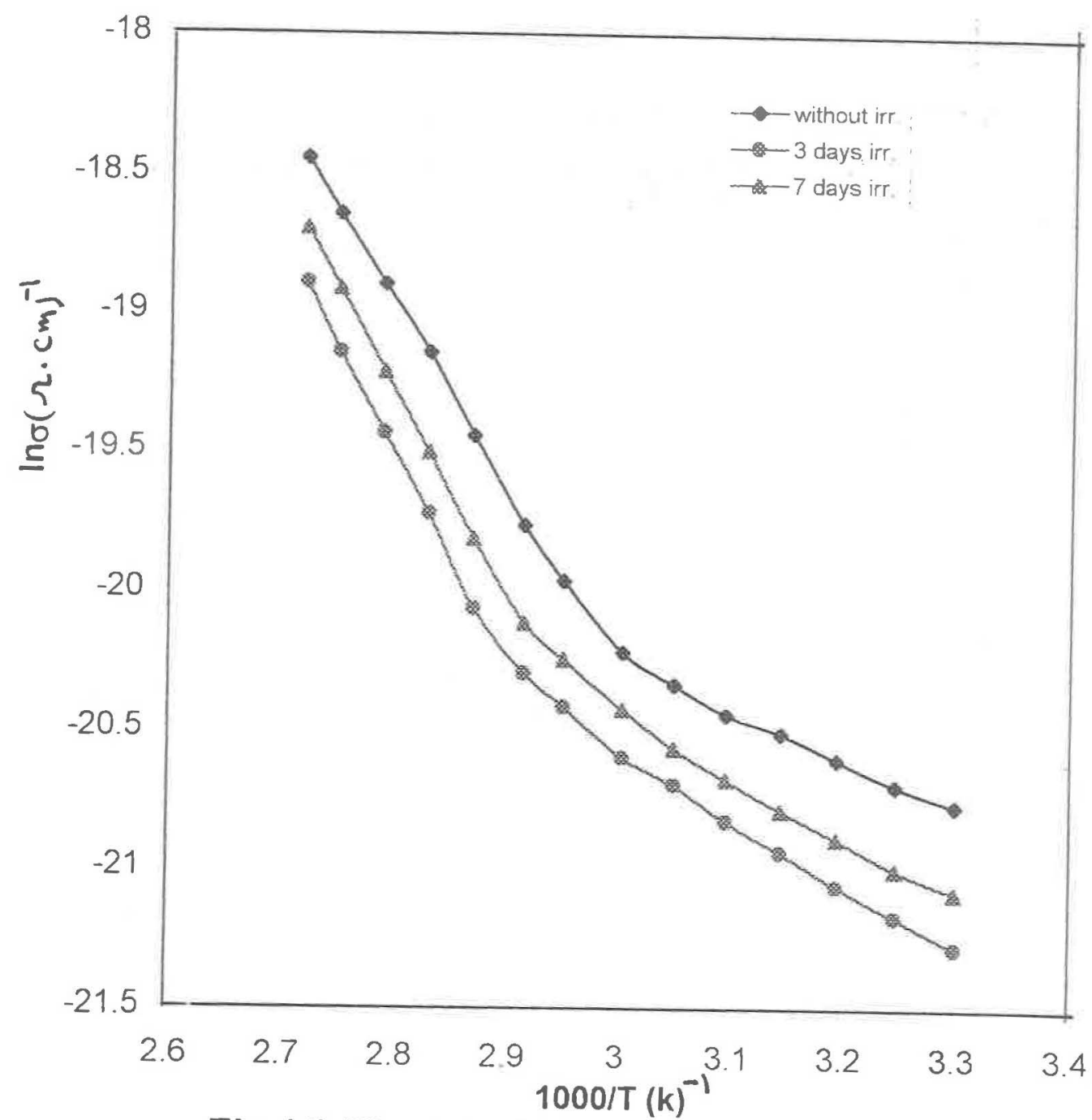

Fig.(4) Electrical conductivity variation with temperature of SMR irradiated by $\beta$ - particles 


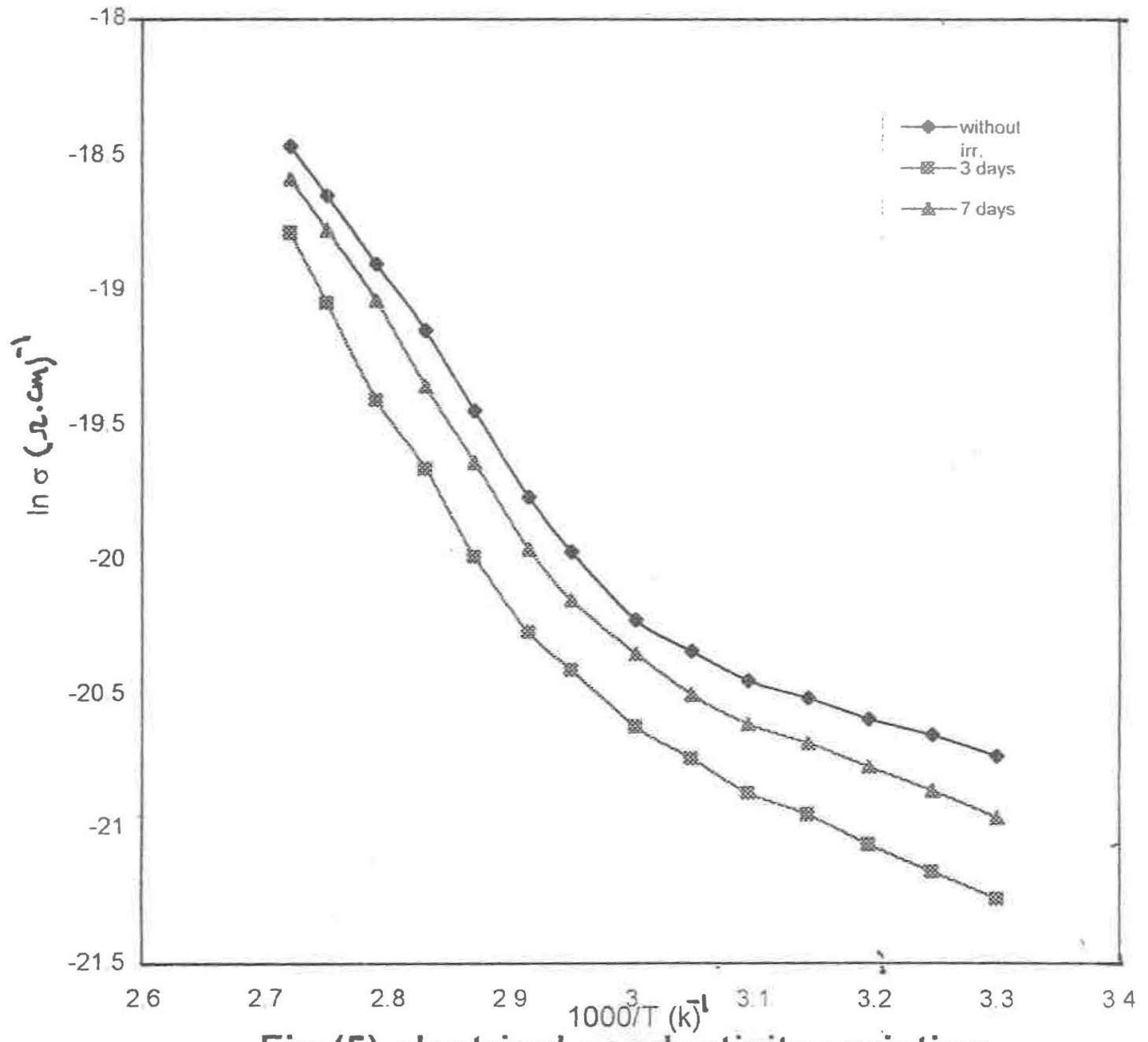

Fig.(5) electrical conductivity variation

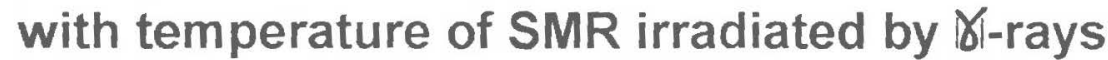




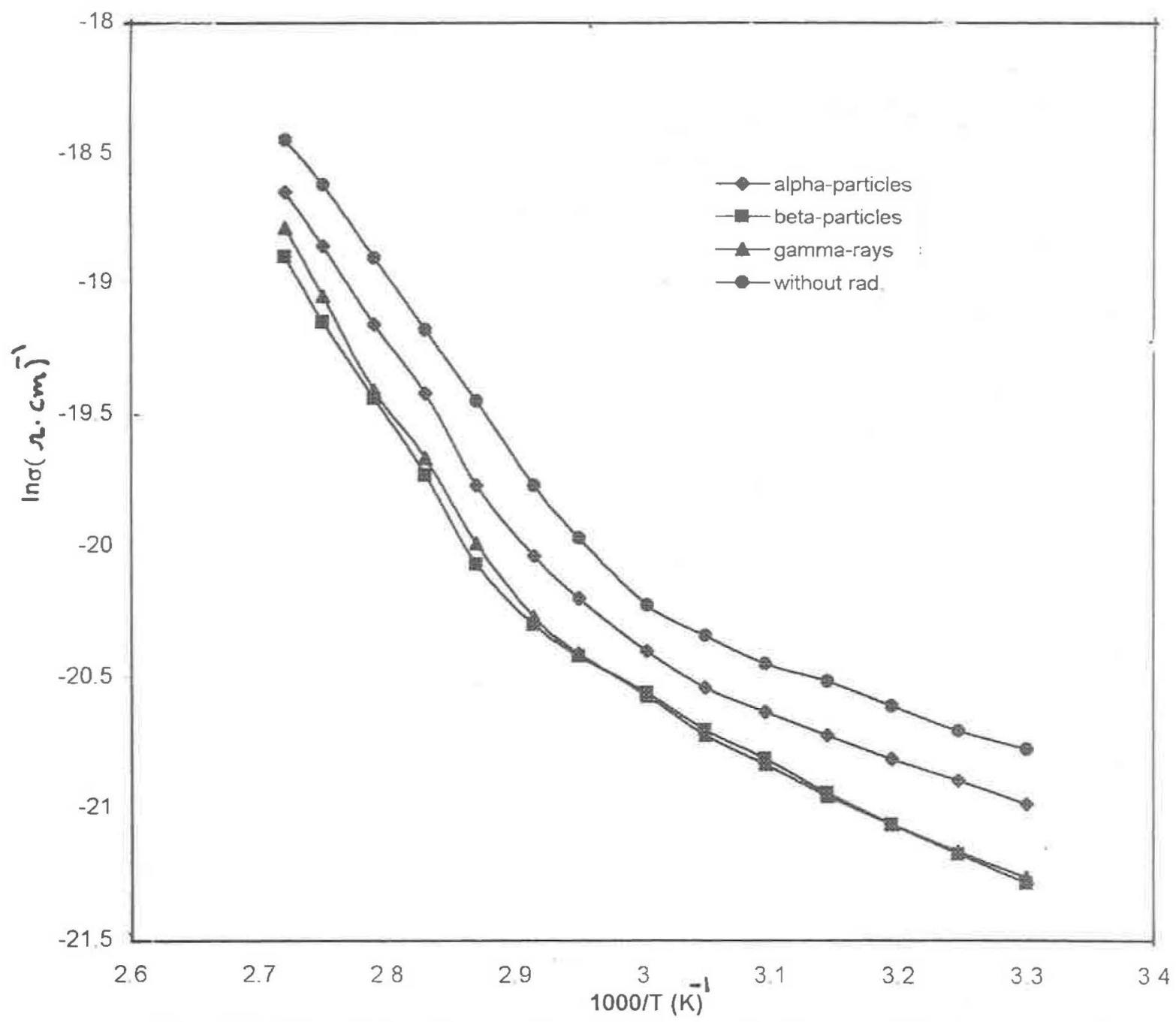

Fig.(6) Electrical conductivity variation with temperature of SMR irradiated with different nuclear radiations for 3-days . 